\title{
Regulator of Angiogenesis and Vascular Function: A 2019 Update of the Vasoinhibin Nomenclature
}

\author{
Jakob Triebel ${ }^{1 *}$, Juan Pablo Robles ${ }^{2}$, Magdalena Zamora ${ }^{2}$, \\ Gonzalo Martínez de la Escalera ${ }^{2}$, Thomas Bertsch ${ }^{1}$ and Carmen Clapp ${ }^{2}$ \\ ${ }^{1}$ Institute for Clinical Chemistry, Laboratory Medicine and Transfusion Medicine, General Hospital Nuremberg and Paracelsus \\ Medical University Nuremberg, Nuremberg, Germany, ${ }^{2}$ Instituto de Neurobiología, Universidad Nacional Autónoma de \\ México, Querétaro, Mexico
}

Keywords: prolactin, growth hormone, placental lactogen, prolactin/vasoinhibin axis, 16K PRL

\section{OPEN ACCESS}

Edited by:

Justo P. Castaño,

Instituto Maimonides de Investigación Biomédica de Cordoba (IMIBIC),

Spain

Reviewed by: Alessandro Cavarape, University of Udine, Italy

*Correspondence: Jakob Triebel Jakob.Triebe/@gmx.de

Specialty section: This article was submitted to Systems and Translational Endocrinology,

a section of the journal Frontiers in Endocrinology

Received: 08 November 2018 Accepted: 18 March 2019 Published: 10 April 2019

Citation:

Triebel J, Robles JP, Zamora M, Martínez de la Escalera G, Bertsch T and Clapp C (2019) Regulator of Angiogenesis and Vascular Function: A 2019 Update of the Vasoinhibin Nomenclature.

Front. Endocrinol. 10:214 doi: 10.3389/fendo.2019.00214
Proteolytic cleavage of prolactin (PRL), the human anterior pituitary hormone fundamental for lactation can generate vasoinhibin, a peptide-hormone with endocrine, paracrine, and autocrine effects not shared with its precursor. Vasoinhibin effects include the regulation of blood vessel growth, permeability, and dilation $(1,2)$, and non-vascular effects such as stimulation of vasopressin release (3), thrombolytic actions (4), inhibition of neurite outgrowth (5), and the stimulation of anxiety- and depression-related behaviors (6). Vasoinhibin signals through a still-unidentified receptor on endothelial cells distinct from the PRL-receptor and interacts with multiple binding partners $(4,7,8)$. The role of vasoinhibin in biology and disease is evolving and its understanding requires the revision of its nomenclature, which is the purpose of this commentary (9).

The regulation of vasoinhibin generation occurs at the hypothalamo, the pituitary, and the target tissue levels and this organizational principle is described as the prolactin/vasoinhibin axis (10). A dysregulation of this axis is relevant in several diseases. Recent studies have focused on retinal disorders $(11,12)$, joint diseases (13), and pregnancy associated syndromes, for example diabetic retinopathy $(11,14)$, rheumatoid arthritis (13), peripartum-cardiomyopathy (15), and pre-eclampsia $(16,17)$. Two clinical trials in which vasoinhibin levels are the target of pharmacological interventions were initiated, one for the treatment of diabetic retinopathy and diabetic macular edema, and another for the treatment of peripartum cardiomyopathy $(18,19)$. The principles and rationales behind these clinical trials were recently reviewed (20). Landmark studies on the physiological and pathophysiological effects of vasoinhibin are presented in Table $\mathbf{1}$.

Historically, vasoinhibin was named " $16 \mathrm{kDa}$ PRL" or " $16 \mathrm{~K}$ fragment of prolactin" referring to the molecular mass of one of its isoforms and to PRL as its precursor $(37,38)$. With the introduction of a new nomenclature in 2006, the term was updated and changed to "vasoinhibin" $(27,45)$ (Figure 1). The introduction of the vasoinhibin nomenclature was triggered by the recognition that PRL fragments with inhibitory effects on blood vessels are not a single $16 \mathrm{kDa}$ species, but rather a family of proteins with different molecular masses (10). As their functional and structural features are unique and contrast with those of full-length PRL, it was recognized that these proteins are sole hormones, and should not bear the same designation as PRL. Further, it was discovered that fragments of growth hormone $(\mathrm{GH})$ and placental lactogen (PL), hormones closely related to PRL, demonstrate similar antiangiogenic properties $(34,46)$. As a family, they were collectively named "vasoinhibins," inspired by their principal effects, the inhibition of blood vessel growth, and control of blood vessel function (45). 
TABLE 1 | Landmark original research articles and reviews highlighting physiology and pathophysiological effects of vasoinhibin.

Brief description References

\section{ORIGINAL RESEARCH ARTICLES}

Model of the three-dimensional structure of vasoinhibin, and localization of its functional domain

Clinical trial protocol on diabetic retinopathy and diabetic macular edema, pharmacological intervention

2018

into regulation of PRL/vasoinhibin axis

Suppression of neurotrophic VEGF and NGF-induced effects

2017

(5)

Findings of a clinical trial on peripartum cardiomyopathy, pharmacological intervention into

2017

PRL/vasoinhibin axis

Binding partners and profibrinolytic action

2014

(4)

Role on mammary gland involution in mice

2014

Effects on anxiety- and depression-like behaviors in rats

2014

(6)

Vasoinhibin gene therapy against diabetic retinopathy protects against VEGF- and diabetes-induced

2011

asopermeability in rats

Hyperprolactinemia in rodents leads to vasoinhibin accumulation in the retina

2010

Cathepsin D generates vasoinhibin in rat anterior pituitary PRL secretory granules

2009

Inhibition of vasopermeability in diabetic retinopathy

2008

Impairment of cardiac capillary proliferation and function in peripartum cardiomyopathy

2007

Vasoinhibin gene therapy against tumor growth and metastasis

2007

Effect on endothelial cell dysfunction and low birth weight in preeclampsia

2007

Bone morphogenetic protein 1 generates vasoinhibin

2007

Matrix metalloproteases generate vasoinhibin

2006

Inhibition of angiogenesis and vasodilation in the rat retina by endogenous vasoinhibin

2005

Stimulation of vasopressin release

2003

Stimulation of ocular vascular regression in retinopathy of prematurity by endogenous vasoinhibin

2004

Inhibition of retinal angiogenesis in oxygen-induced retinopathy in mice

2004

Inhibition of tumor growth in human colon cancer cells transplanted into mice

2001

Proinflammatory effects in pulmonary fibroblasts and alveolar type II cells

2000

Vasoinhibin contains the $\mathrm{N}$-terminal region of $\mathrm{PRL}$

1999

Opposite effects of PRL and vasoinhibin on angiogenesis

1999

Inhibition of corneal angiogenesis by exogenous and endogenous vasoinhibin

1999

Cathepsin D generates vasoinhibin

1993

Inhibition of in vitro and in vivo angiogenesis

1993

Specific vasoinhibin binding sites in endothelial cell membranes

1992

Discovery of antiangiogenic properties

1991

Detection of vasoinhibin in the human pituitary gland and plasma

1985

Cleavage of $P R L$ by target tissues

Discovery of vasoinhibin as a functional PRL fragment in rat pituitary tissue

1983

\section{REVIEW ARTICLES}

Translational research, focus on diabetic retinopathy and peripartum cardiomyopathy

1980

Involvement of the PRL/vasoinhibin axis in rheumatoid arthritis

2017

(20)

First description of the PRL/vasoinhibin endocrine axis

2016

(13)

Pathophysiological role of vasoinhibin in peripartum cardiomyopathy

2015

Physiological and pathophysiological roles

2014

Actions on mammary gland

2009

(2)

Biology of vasoinhibin, vascular effects, and signal transduction

2008

Prolactin-, growth hormone-, and placental lactogen derived vasoinhibin and its effect on angiogenesis

2006

2002

(46)

Nearly 40 years of research since the discovery of vasoinhibin in 1980 resulted in a series of insights into the function and regulation of vasoinhibin. The latest developments feature

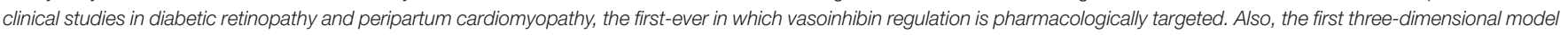

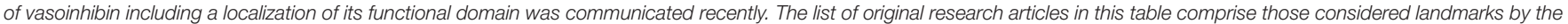
authors, however, there are more relevant articles discussed and cited in the reviews listed at the end of the table. 


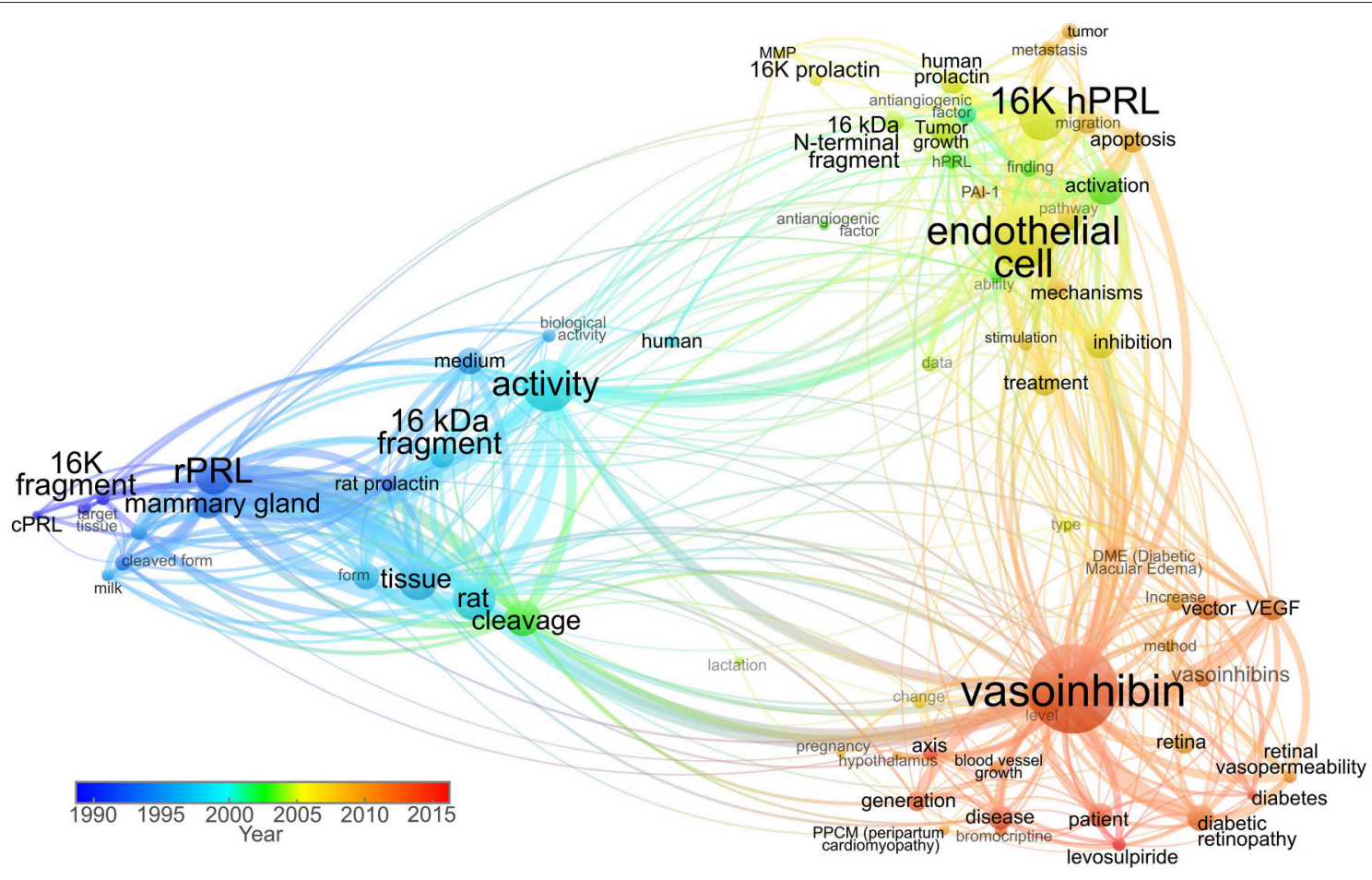

FIGURE 1 | Term co-occurrence map analyzing the use of vasoinhibin-related names in titles and abstracts throughout time. Scientific articles published between 1980 and 1999 used terms such as "16K fragment," "CPRL" (cleaved prolactin), and "16 kDa fragment" as valid nomenclature. The predominant "16K hPRL" term was then used in combination with "16K prolactin" and "16 kDa N-terminal fragment" up to 2006, when the "vasoinhibin" term was introduced. In recent years, the "vasoinhibin" word shows higher frequency, whereas the 16K-related shows progressive lower incidence. The size of the node represents the frequency of term appearance. The lines between terms indicate relations with smaller distances representing stronger associations. The color indicates average year of term appearance. The map was created and visualized using VOSviewer software tool (47) in which the network was constructed employing 71 terms with more than $60 \%$ relevance, selected from 119 words surpassing the seven-appearance threshold, in titles and abstracts of 93 research publications accessed through Scopus.

In the years ensuing the introduction of the vasoinhibin nomenclature, a heterogeneous use of the terminology was observed (Figure 1). Some kept using the historic designation "16 $\mathrm{kDa}$ PRL fragment," in some instances due to the convenience of highlighting the PRL-related context of its action (48); others used " $16 \mathrm{kDa}$ vasoinhibin," the term in its plural form "vasoinhibins," or a combination of these designations $(9,15,22)$. In an attempt to identify the precursor of vasoinhibin, and to discriminate it from vasoinhibin of other origin (for example GH or PL-derived), it was also referred to as "prolactin-derived vasoinhibins" or "prolactinrelated vasoinhibin" $(6,49)$. Also, numbering the vasoinhibin isoforms in order to designate their origin and to state the molecular mass of each isoform was suggested (50). Of note, in communication with journals and in peer-review procedures, the designation "vasoinhibin" was confused with "vasohibin," a new term for a protein unrelated to vasoinhibin which was introduced around the same time than the vasoinhibin nomenclature (51).

It became clear, that the heterogeneous use of other terms for vasoinhibin is unfavorable as it complicates orientation and introduces inaccuracies when using search engines. Moreover, a uniform nomenclature to correctly and completely annotate the growing biological and clinical information about vasoinhibin in data bases is required. The use of the terms " $16 \mathrm{kDa}$ PRL" and the like, as listed above, can no longer be recommended, as they are outdated (Figure 1) and do not conform with the International Protein Nomenclature Guidelines (IPNG) (52) in which both, the use of the molecular mass $(16 \mathrm{kDa})$, and ambiguity (PRL) is discouraged. Therefore, in line with the published literature, and with the IPNG, we suggest using the term "vasoinhibin" for a peptide hormone fulfilling the following criteria:

- The protein is generated by post-translational processing, i.e., proteolytic cleavage, of PRL, GH, or PL (UniProt ID P01236, P01241, and P0DML2).

- The protein demonstrates inhibition of endothelial cell proliferation and inhibition of angiogenesis in in vitro and in vivo bioassays, respectively.

- Having the vasoinhibin bioactive domain architecture and solution structure is emerging as a third criterion (21), but requires further experimental validation and is, therefore, projected as a future criterion. 
The criteria $\mathrm{A}, \mathrm{B}$, and $\mathrm{C}$ correspond to the IPNG rank of sources, whereas criteria $\mathrm{B}$ and $\mathrm{C}$ also correspond to experimental reports and domain architecture, respectively. Other rank denominations (established and maintained database authorities), models (Hidden Markov models), and signatures are not yet available.

The criteria are based on present knowledge and should not be interpreted as final as it is possible that vasoinhibin of other origin than PRL, GH, and PL will be discovered. In case of similar biological activity and domain architecture, such protein would consequently receive the designation vasoinhibin or vasoinhibin-domain containing protein. Therefore, we also recommend maintaining the inclusive designation of "vasoinhibin-family" when addressing the entirety of known and/or undiscovered vasoinhibin (-like) hormones. Also, as vasoinhibin is a pleiotropic hormone, it remains to be investigated whether all its diverse effects are mediated by one or more bioactive domains.

\section{REFERENCES}

1. Clapp C, Thebault S, Macotela Y, Moreno-Carranza B, Triebel J, Martinez de la Escalera G. Regulation of blood vessels by prolactin and vasoinhibins. Adv Exp Med Biol. (2015) 846:83-95. doi: 10.1007/978-3-31912114-7_4

2. Clapp C, Thebault S, Jeziorski MC, Martinez De La Escalera G. Peptide hormone regulation of angiogenesis. Physiol Rev. (2009) 89:1177-215. doi: 10.1152/physrev.00024.2009

3. Mejia S, Torner LM, Jeziorski MC, Gonzalez C, Morales MA, de la Escalera GM, et al. Prolactin and $16 \mathrm{~K}$ prolactin stimulate release of vasopressin by a direct effect on hypothalamo-neurohypophyseal system. Endocrine. (2003) 20:155-62. doi: 10.1385/ENDO:20:1-2:155

4. Bajou K, Herkenne S, Thijssen VL, D’Amico S, Nguyen NQ, Bouche A, et al. PAI-1 mediates the antiangiogenic and profibrinolytic effects of $16 \mathrm{~K}$ prolactin. Nat Med. (2014) 20:741-7. doi: 10.1038/nm.3552

5. Castillo X, Melo Z, Varela-Echavarria A, Tamariz E, Arona RM, Arnold E, et al. Vasoinhibin suppresses the neurotrophic effects of VEGF and NGF in newborn rat primary sensory neurons. Neuroendocrinology. (2018) 106:22133. doi: $10.1159 / 000477768$

6. Zamorano M, Ledesma-Colunga MG, Adan N, Vera-Massieu C, Lemini M, Mendez I, et al. Prolactin-derived vasoinhibins increase anxiety- and depression-related behaviors. Psychoneuroendocrinology. (2014) 44:123-32. doi: 10.1016/j.psyneuen.2014.03.006

7. Clapp C, Weiner RI. A specific, high affinity, saturable binding site for the 16kilodalton fragment of prolactin on capillary endothelial cells. Endocrinology. (1992) 130:1380-6.

8. Morohoshi K, Mochinaga R, Watanabe T, Nakajima R, Harigaya T. 16 kDa vasoinhibin binds to integrin alpha5 beta1 on endothelial cells to induce apoptosis. Endocr Connect. (2018) 7:630-6. doi: 10.1530/EC-18-0116

9. Triebel J, Bertsch T, Martinez de la Escalera G, Clapp C. On the path toward classifying hormones of the vasoinhibin-family. Front Endocrinol. (2015) 6:16. doi: 10.3389/fendo.2015.00016

10. Triebel J, Bertsch T, Bollheimer C, Rios-Barrera D, Pearce CF, Hufner M, et al. Principles of the prolactin/vasoinhibin axis. Am J Physiol Regul Integr Compar Physiol. (2015) 309:R1193-203. doi: 10.1152/ajpregu.00256.2015

11. Arnold E, Rivera JC, Thebault S, Moreno-Paramo D, Quiroz-Mercado H, Quintanar-Stephano A, et al. High levels of serum prolactin protect against diabetic retinopathy by increasing ocular vasoinhibins. Diabetes. (2010) 59:3192-7. doi: 10.2337/db10-0873

12. Zepeda-Romero LC, Vazquez-Membrillo M, Adan-Castro E, GomezAguayo F, Gutierrez-Padilla JA, Angulo-Castellanos E, et al. Higher prolactin and vasoinhibin serum levels associated with incidence and
The present commentary reflects on the history of the nomenclature used for vasoinhibin (Figure 1), and recommends, based on the latest literature and the protein nomenclature guidelines, how to handle this nomenclature in scientific publications and data bank entries. We believe that consideration of the present recommendations will improve the accuracy of scientific communication and hereby benefit the field.

\section{AUTHOR CONTRIBUTIONS}

JT, JPR, and CC wrote the manuscript. MZ, GMdelaE, and TB edited and revised the manuscript. All authors approved the manuscript.

\section{FUNDING}

Supported by the National Council of Science and Technology of Mexico (CONACYT grant 289568) to CC.

progression of retinopathy of prematurity. Pediatr Res. (2017) 81:473-9. doi: $10.1038 /$ pr.2016.241

13. Clapp C, Adan N, Ledesma-Colunga MG, Solis-Gutierrez M, Triebel J, Martinez de la Escalera G. The role of the prolactin/vasoinhibin axis in rheumatoid arthritis: an integrative overview. Cell Mol Life Sci. (2016) 73:2929-48. doi: 10.1007/s00018-016-2187-0

14. Ramirez M, Wu Z, Moreno-Carranza B, Jeziorski MC, Arnold E, DiazLezama $\mathrm{N}$, et al. Vasoinhibin gene transfer by adenoassociated virus type 2 protects against VEGF- and diabetes-induced retinal vasopermeability. Invest Ophthalmol Visual Sci. (2011) 52:8944-50. doi: 10.1167/iovs.11-8190

15. Hilfiker-Kleiner D, Kaminski K, Podewski E, Bonda T, Schaefer A, Sliwa K, et al. A cathepsin D-cleaved $16 \mathrm{kDa}$ form of prolactin mediates postpartum cardiomyopathy. Cell. (2007) 128:589-600. doi: 10.1016/j.cell.2006. 12.036

16. Reuwer AQ, Reuwer PJ, van der Post JA, Cramer MJ, Kastelein JJ, Twickler MT. Prolactin fragmentation by trophoblastic matrix metalloproteinases as a possible contributor to peripartum cardiomyopathy and pre-eclampsia. Med Hypotheses. (2010) 74:348-52. doi: 10.1016/j.mehy.2009.08.029

17. Gonzalez C, Parra A, Ramirez-Peredo J, Garcia C, Rivera JC, Macotela Y, et al. Elevated vasoinhibins may contribute to endothelial cell dysfunction and low birth weight in preeclampsia. Lab Invest. (2007) 87:1009-17. doi: 10.1038/labinvest.3700662

18. Hilfiker-Kleiner D, Haghikia A, Berliner D, Vogel-Claussen J, Schwab J, Franke A, et al. Bromocriptine for the treatment of peripartum cardiomyopathy: a multicentre randomized study. Eur Heart J. (2017) 38:2671-9. doi: 10.1093/eurheartj/ehx355

19. Robles-Osorio ML, Garcia-Franco R, Nunez-Amaro CD, Mira-Lorenzo X, Ramirez-Neria P, Hernandez W, et al. Basis and design of a randomized clinical trial to evaluate the effect of levosulpiride on retinal alterations in patients with diabetic retinopathy and diabetic macular edema. Front Endocrinol. (2018) 9:242. doi: 10.3389/fendo.2018.00242

20. Triebel J, Robles-Osorio ML, Garcia-Franco R, Martinez de la Escalera G, Clapp C, Bertsch T. From bench to bedside: translating the prolactin/vasoinhibin axis. Front Endocrinol. (2017) 8:342. doi: $10.3389 /$ fendo.2017.00342

21. Robles JP, Zamora M, Velasco-Bolom JL, Tovar M, Garduno-Juarez R, Bertsch $\mathrm{T}$, et al. Vasoinhibin comprises a three-helix bundle and its antiangiogenic domain is located within the first 79 residues. Sci Rep. (2018) 8:17111. doi: 10.1038/s41598-018-35383-7

22. Ishida $M$, Maehara $M$, Watanabe $T$, Yanagisawa $Y$, Takata $Y$, Nakajima $\mathrm{R}$, et al. Vasoinhibins, N-terminal mouse prolactin fragments, participate in mammary gland involution. J Mol Endocrinol. (2014) 52:279-87. doi: 10.1530/JME-13-0189 
23. Cruz-Soto ME, Cosio G, Jeziorski MC, Vargas-Barroso V, Aguilar $\mathrm{MB}$, Carabez A, et al. Cathepsin D is the primary protease for the generation of adenohypophyseal vasoinhibins: cleavage occurs within the prolactin secretory granules. Endocrinology. (2009) 150:5446-54. doi: 10.1210/en.2009-0390

24. Garcia C, Aranda J, Arnold E, Thebault S, Macotela Y, Lopez-Casillas F, et al. Vasoinhibins prevent retinal vasopermeability associated with diabetic retinopathy in rats via protein phosphatase $2 \mathrm{~A}$-dependent eNOS inactivation. J Clin Invest. (2008) 118:2291-300. doi: 10.1172/JCI34508

25. Nguyen NQ, Cornet A, Blacher S, Tabruyn SP, Foidart JM, Noel A, et al. Inhibition of tumor growth and metastasis establishment by adenovirusmediated gene transfer delivery of the antiangiogenic factor 16K hPRL. Mol Ther. (2007) 15:2094-100. doi: 10.1038/sj.mt.6300294

26. Ge G, Fernandez CA, Moses MA, Greenspan DS. Bone morphogenetic protein 1 processes prolactin to a $17-\mathrm{kDa}$ antiangiogenic factor. Proc Natl Acad Sci USA. (2007) 104:10010-5. doi: 10.1073/pnas.0704179104

27. Macotela Y, Aguilar MB, Guzman-Morales J, Rivera JC, Zermeno C, LopezBarrera F, et al. Matrix metalloproteases from chondrocytes generate an antiangiogenic $16 \mathrm{kDa}$ prolactin. J Cell Sci. (2006) 119(Pt 9):1790-800. doi: $10.1242 /$ jcs. 02887

28. Aranda J, Rivera JC, Jeziorski MC, Riesgo-Escovar J, Nava G, LopezBarrera F, et al. Prolactins are natural inhibitors of angiogenesis in the retina. Invest Ophthalmol Visual Sci. (2005) 46:2947-53. doi: 10.1167/iovs. 05-0173

29. Duenas Z, Rivera JC, Quiroz-Mercado H, Aranda J, Macotela Y, Montes de Oca $\mathrm{P}$, et al. Prolactin in eyes of patients with retinopathy of prematurity: implications for vascular regression. Invest Ophthalmol Visual Sci. (2004) 45:2049-55. doi: 10.1167/iovs.03-1346

30. Pan H, Nguyen NQ, Yoshida H, Bentzien F, Shaw LC, Rentier-Delrue F, et al. Molecular targeting of antiangiogenic factor 16K hPRL inhibits oxygeninduced retinopathy in mice. Invest Ophthalmol Visual Sci. (2004) 45:2413-9. doi: 10.1167/iovs.03-1001

31. Bentzien F, Struman I, Martini JF, Martial J, Weiner R. Expression of the antiangiogenic factor 16K hPRL in human HCT116 colon cancer cells inhibits tumor growth in Rag1(-/-) mice. Cancer Res. (2001) 61:7356-62.

32. Corbacho AM, Nava G, Eiserich JP, Noris G, Macotela Y, Struman I, et al. Proteolytic cleavage confers nitric oxide synthase inducing activity upon prolactin. J Biol Chem. (2000) 275:13183-6. doi: 10.1074/jbc.275.18. 13183

33. Khurana S, Liby K, Buckley AR, Ben-Jonathan N. Proteolysis of human prolactin: resistance to cathepsin D and formation of a nonangiostatic, Cterminal $16 \mathrm{~K}$ fragment by thrombin. Endocrinology. (1999) 140:4127-32. doi: 10.1210/endo.140.9.6955

34. Struman I, Bentzien F, Lee H, Mainfroid V, D'Angelo G, Goffin V, et al. Opposing actions of intact and N-terminal fragments of the human prolactin/growth hormone family members on angiogenesis: an efficient mechanism for the regulation of angiogenesis. Proc Natl Acad Sci USA. (1999) 96:1246-51. doi: 10.1073/pnas.96.4.1246

35. Duenas Z, Torner L, Corbacho AM, Ochoa A, Gutierrez-Ospina G, LopezBarrera $\mathrm{F}$, et al. Inhibition of rat corneal angiogenesis by $16-\mathrm{kDa}$ prolactin and by endogenous prolactin-like molecules. Invest Ophthalmol Visual Sci. (1999) 40:2498-505.

36. Baldocchi RA, Tan L, King DS, Nicoll CS. Mass spectrometric analysis of the fragments produced by cleavage and reduction of rat prolactin: evidence that the cleaving enzyme is cathepsin D. Endocrinology. (1993) 133:935-8. doi: 10.1210/endo.133.2.8344226

37. Clapp C, Martial JA, Guzman RC, Rentier-Delure F, Weiner RI. The 16-kilodalton N-terminal fragment of human prolactin is a potent inhibitor of angiogenesis. Endocrinology. (1993) 133:1292-9. doi: 10.1210 /endo.133.3.7689950
38. Ferrara N, Clapp C, Weiner R. The $16 \mathrm{~K}$ fragment of prolactin specifically inhibits basal or fibroblast growth factor stimulated growth of capillary endothelial cells. Endocrinology. (1991) 129:896-900. doi: 10.1210/endo-129-2-896

39. Sinha YN, Gilligan TA, Lee DW, Hollingsworth D, Markoff E. Cleaved prolactin: evidence for its occurrence in human pituitary gland and plasma. J Clin Endocrinol Metabol. (1985) 60:239-43. doi: 10.1210/jcem-60-2-239

40. Compton MM, Witorsch RJ. Proteolytic fragmentation of rat prolactin by the rat ventral prostate gland. Prostate. (1983) 4:231-46. doi: $10.1002 /$ pros.2990040303

41. Mittra I. A novel "cleaved prolactin" in the rat pituitary: part II. In vivo mammary mitogenic activity of its N-terminal 16K moiety. Biochem Biophys Res Commun. (1980) 95:1760-7. doi: 10.1016/S0006-291X(80)80102-1

42. Mittra I. A novel "cleaved prolactin" in the rat pituitary: part I. Biosynthesis, characterization and regulatory control. Biochem Biophys Res Commun. (1980) 95:1750-9. doi: 10.1016/S0006-291X(80)80101-X

43. Hilfiker-Kleiner D, Sliwa K. Pathophysiology and epidemiology of peripartum cardiomyopathy. Nat Rev Cardiol. (2014) 11:364-70. doi: $10.1038 /$ nrcardio. 2014.37

44. Clapp C, Thebault S, Martinez de la Escalera G. Role of prolactin and vasoinhibins in the regulation of vascular function in mammary gland. J Mammary Gland Biol Neoplasia. (2008) 13:55-67. doi: 10.1007/s10911-008-9067-7

45. Clapp C, Aranda J, Gonzalez C, Jeziorski MC, Martinez de la Escalera G. Vasoinhibins: endogenous regulators of angiogenesis and vascular function. Trends Endocrinol Metabol. (2006) 17:301-7. doi: 10.1016/j.tem.2006.08.002

46. Corbacho AM, Martinez De La Escalera G, Clapp C. Roles of prolactin and related members of the prolactin/growth hormone/placental lactogen family in angiogenesis. J Endocrinol. (2002) 173:219-38. doi: 10.1677/joe.0.1730219

47. van Eck NJ, Waltman L. Software survey: VOSviewer, a computer program for bibliometric mapping. Scientometrics. (2010) 84:523-38. doi: 10.1007/s11192-009-0146-3

48. Yun B-Y, Cho C, Cho B-N. Differential activity of $16 \mathrm{~K}$ rat prolactin in different organic systems. Anim Cells Syst. (2019):54:1-8. doi: 10.1080/19768354.2018.1554543

49. Triebel J, Huefner M, Ramadori G. Investigation of prolactin-related vasoinhibin in sera from patients with diabetic retinopathy. Eur J Endocrinol. (2009) 161:345-53. doi: 10.1530/EJE-09-0130

50. Vazquez Rodriguez G, Gonzalez C, De Leon Rodriguez A. Novel fusion protein derived from vasostatin 30 and vasoinhibin II-14.1 potently inhibits coronary endothelial cell proliferation. Mol Biotechnol. (2013) 54:920-9. doi: 10.1007/s12033-012-9642-4

51. Watanabe K, Hasegawa Y, Yamashita H, Shimizu K, Ding Y, Abe M, et al. Vasohibin as an endothelium-derived negative feedback regulator of angiogenesis. J Clin Invest. (2004) 114:898-907. doi: 10.1172/JCI200421152

52. International Protein Nomenclature Guidelines. (2018). Available online at: https://www.uniprot.org/docs/International_Protein_Nomenclature_Guideli nes.pdf (accessed March 27, 2018).

Conflict of Interest Statement: The authors declare that the research was conducted in the absence of any commercial or financial relationships that could be construed as a potential conflict of interest.

Copyright (c) 2019 Triebel, Robles, Zamora, Martínez de la Escalera, Bertsch and Clapp. This is an open-access article distributed under the terms of the Creative Commons Attribution License (CC BY). The use, distribution or reproduction in other forums is permitted, provided the original author(s) and the copyright owner(s) are credited and that the original publication in this journal is cited, in accordance with accepted academic practice. No use, distribution or reproduction is permitted which does not comply with these terms. 